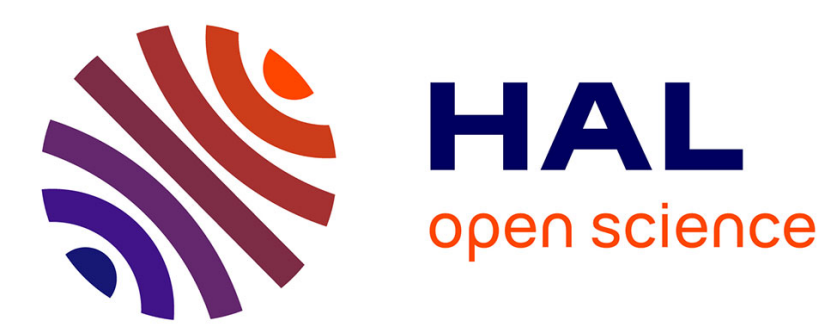

\title{
Sraffa's System: Equal Rate of Profits and the Notion of Centre of Gravitation
}

\author{
Ajit Sinha, Michel-Stéphane Dupertuis
}

\section{To cite this version:}

Ajit Sinha, Michel-Stéphane Dupertuis. Sraffa's System: Equal Rate of Profits and the Notion of Centre of Gravitation. Journal of Economic Behavior and Organization, 2009, 71 (2), pp.495. 10.1016/j.jebo.2009.03.014 . hal-00683159

\section{HAL Id: hal-00683159 \\ https://hal.science/hal-00683159}

Submitted on 28 Mar 2012

HAL is a multi-disciplinary open access archive for the deposit and dissemination of scientific research documents, whether they are published or not. The documents may come from teaching and research institutions in France or abroad, or from public or private research centers.
L'archive ouverte pluridisciplinaire HAL, est destinée au dépôt et à la diffusion de documents scientifiques de niveau recherche, publiés ou non, émanant des établissements d'enseignement et de recherche français ou étrangers, des laboratoires publics ou privés. 


\section{Accepted Manuscript}

Title: Sraffa's System: Equal Rate of Profits and the Notion of Centre of Gravitation

Authors: Ajit Sinha, Michel-Stéphane Dupertuis

PII: $\quad$ S0167-2681(09)00081-X

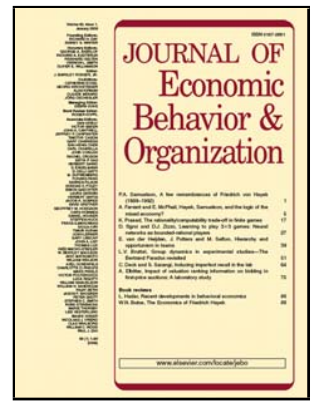

DOI: $\quad$ doi:10.1016/j.jebo.2009.03.014

Reference: $\quad$ JEBO 2353

To appear in: Journal of Economic Behavior \& Organization

Received date: $\quad 9-1-2008$

Revised date: $\quad 18-3-2009$

Accepted date: $\quad$ 18-3-2009

Please cite this article as: Sinha, A., Dupertuis, M.-S., Sraffa's System: Equal Rate of Profits and the Notion of Centre of Gravitation, Journal of Economic Behavior and Organization (2008), doi:10.1016/j.jebo.2009.03.014

This is a PDF file of an unedited manuscript that has been accepted for publication. As a service to our customers we are providing this early version of the manuscript. The manuscript will undergo copyediting, typesetting, and review of the resulting proof before it is published in its final form. Please note that during the production process errors may be discovered which could affect the content, and all legal disclaimers that apply to the journal pertain. 
Sraffa's System: Equal Rate of Profits and the Notion of Centre of Gravitation

Ajit Sinha

Sinha a99@yahoo.com

Michel-Stéphane Dupertuis

msdupertuis@vtxnet.ch 


\title{
Sraffa's System: Equal Rate of Profits and the Notion of Centre of Gravitation
}

\author{
Ajit Sinha \\ Sinha a99@yahoo.com \\ Michel-Stéphane Dupertuis \\ msdupertuis@vtxnet.ch
}

\begin{abstract}
This paper argues that the condition of uniform rate of profits in Sraffa's system is not based on his implicit assumption that the system is at the 'equilibrium' or the center of gravitation. It is rather a logical requirement of a reproducing system of basic goods as long as prices are not imposed from outside the system. This condition holds irrespective of supplies being equal to their respective effectual demands. It conjectures that Sraffa could have arrived at this conclusion through his analysis of the Standard system. On the basis of this result, a critique of the received interpretation, led by Garegnani, of Sraffa's prices is developed.
\end{abstract}

\section{Introduction}

In this paper we provide an interpretation of a cryptic remark of Sraffa (1960) which provides a new perspective to an interpretation of his book. We argue that the equalization of the rate of profits in Sraffa's systems is not necessarily based on an implicit assumption of the equalization of the quantities supplied with the quantities demanded of all the commodities in his system. Irrespective of the equilibrium of demand and supply, it is an inherent property of an interlinked system of basic goods that its sectoral rate of profits would be equal as long as the system is free from imposition of prices from outside the system.

In Chapter 1 of his book, Sraffa (1960, p. 3) establishes the fact that in a 'subsistence economy' the relative prices of commodities "spring directly from the methods of production" because such a system, represented by its inputs and outputs, has, 
in general, n-1 relative prices as unknowns with n-1 independent equations. In Chapter 2, Sraffa begins by stating, "If the economy produces more than the minimum necessary for replacement and there is a surplus to be distributed, the system becomes selfcontradictory" (p. 6). Now we have $\mathrm{n}$ independent equations with only n-1 unknown relative prices. The surplus produce, however, cannot be distributed prior to the determination of prices as profits are reckoned as a proportion to capital investment and such a proportion between collections of heterogeneous goods cannot be determined prior to the knowledge of prices. Hence, Sraffa goes on to add: "Accordingly we add the rate of profits (which must be uniform for all industries) as an unknown which we call $\mathrm{r}$..." (p. 6, emphasis added). Both the Sraffians (e.g. Garegnani 1976, 1984, 1990a, 1990b, 1990c, 1998, 2000) and the Neoclassicals (e.g. Hahn, 1982) ${ }^{1}$ have read it as an endorsement of the idea of centre of gravitation, where the system is assumed to have settled at the equilibrium, ${ }^{2}$ but if this were the case, then one would have expected Sraffa to have written: 'which should or ought to be uniform in equilibrium'. However, he uses a cryptic "must" without even a qualification about equilibrium. In fact the very first sentence of the 'Preface' of the book announces that: "Anyone accustomed to think in terms of equilibrium of demand and supply may be inclined, on reading these pages, to

\footnotetext{
${ }^{1}$ On the basis of our interpretation of Sraffa's condition of the uniform rate of profit in his system, a critique of Hahn is developed elsewhere in Sinha and Dupertuis (2009).

${ }^{2}$ Among the Sraffians, Roncaglia (1978, p. 16) did appreciate that "there is no reason to believe that Sraffa's prices of production should equate quantity demanded and quantity supplied"; however, he did not manage to show how then Sraffa could take the rate of profits to be uniform and thus succumbed to holding the contradictory position that Sraffa's system was a snapshot of the market place as well as his system was assumed to be at the centre of gravitation. Among the neoclassicals, Hicks (1985, p. 306) was one who categorically rejected the centre of gravitation thesis for Sraffa's prices: "Sraffa leaves us to find out what his prices are, but I doubt if they are equilibrium prices. They seem to be prices which are set upon products, by their producers, according to some rule. Now it is perfectly true that we are nowadays familiar with that method of price-fixing, by 'mark-up'; but when that method is used, the rate of profit that is used to establish the mark-up is conventional. Now it may be that Sraffa wants us to think of his rate of profit as being conventional; and that the uniformity of the rate of profit throughout his system, of which he makes so much, is just a uniformity of convention."
} 
suppose that the argument rests on a tacit assumption of constant returns in all industries. ... In fact, however, no such assumption is made" (p. v, emphasis added). Thus thinking in terms of equilibrium of demand and supply is clearly denied, and the choice of the cryptic "must" apparently points to a logical necessity rather than an assumed outcome of the behaviour of a system.

As a matter of fact, during the period of his early theoretical breakthrough, from late 1927 to 1931 (see Garegnani, 2005, p. 475), we find Sraffa to be worried about how to "justify or explain the equal percentage added to initial stock of each industry." After arguing that capital might not be reinvested in the sectors having lower rate of profits and thus not being able to reproduce itself in the long run, he goes on to add, "in this way we are allowing to come back through the window the [notion of cost as] 'inducement' we had excluded from the door [PSP D3/12/6]" (quoted in Garegnani 2005, p. 475, emphasis added; PSP stands for 'Piero Sraffa Papers', the unpublished notes of Sraffa housed in Wren Library, Trinity College, D3 etc. are the reference numbers of the files). During the same period, we find him writing in another note: "I must find a 'force' capable of obliging those people in the market to actuate my equations" (D3/12/7/107-14,). ${ }^{3}$ It should be noted that Sraffa had taken a philosophical or methodological position that the theoretical understanding must be built only on things that are ideally observable and thus no subjective element should enter his equations. Furthermore, during the same period, Sraffa in an attempt to explain the meaning of his equations writes, "The significance of the equations is simply this: that if a man fell from the moon on the earth, and noted the amount of things consumed in each factory $[\ldots]$ during a year he could

\footnotetext{
${ }^{3}$ I am obliged to Nerio Naldi for the English translation of the original in Italian, "devo trovare una $<<$ forza $>>$ che costringa quella brava gente sul mercato a realizzare le mie equazioni."
} 
deduce at which values the commodities must be sold, if the rate of interest must be uniform and the process of production repeated. In short, the equations show that the conditions of exchange are entirely determined by the conditions of production" (PSP, D3/12/7). The reader should take note of the qualifier, "if the rate of interest must be uniform". Interestingly, the qualifier "if" disappears from the relevant passage in the book! What could have happened between the early breakthrough and the publication of the book in 1960 ?

To the best of our knowledge, Sraffa has not left any clear account of how he came to resolve the problem of: how to "justify or explain the equal percentage added to initial stock of each industry"? In his response to Harrod's review of his book, Sraffa (1962, p. 477), however, gives a hint to the fact that his prices are not necessarily the equilibrium prices when he writes, "Now this is clearly a misunderstanding, since the exchange ratios are, of course, determined by the equations of production and not by the ratios between the excess productions of the commodities." We conjecture that it was the discovery of the Standard system and the Standard commodity in the early 1940s which could have convinced Sraffa that the uniformity of the rate of profits was a logical necessity of any given system of production that determines prices internally, irrespective of the equilibrium of demand and supply.

In what follows, in Section 2, we describe the nature of Sraffa's proposition regarding the uniform rate of profits and prove that any given system of basic goods that is able to reproduce itself will distribute its profits according to equal rate to all its sectors as long as no outside constraints are imposed on the system. In Section 3, we critique the arguments and evidence put forward in favour of the received interpretation of the 
condition of the equal rate of profits in Sraffa's system based on the classical notion of centre of gravitation. Section 4 contains a few brief concluding remarks.

\section{The Nature of 'uniform rate of profits' in Sraffa}

Let us take Sraffa's example of three sector economy given on page 19 of his book:

90t. iron +120 t. coal +60 qr. wheat $+3 / 16$ labour $\rightarrow 180$ t. iron

50t. iron +125 t. coal +150 qr. wheat $+5 / 16$ labour $\rightarrow 450 t$. coal I

$40 \mathrm{t}$. iron $+40 \mathrm{t}$. coal +200 qr. wheat $+8 / 16$ labour $\rightarrow 480$ qr. wheat

(For simplicity sake, we will assume wages of labour to be equal to zero). It is clear that Sraffa's statement regarding the rate of profits being "a proportion between two aggregates of heterogeneous goods" $(1960$, p. 6) relates to the net physical output divided by the aggregate of physical inputs of the system, as such a statement will be meaningless at the industry or sectoral level since at these levels the physical surplus remains undefined. Thus what we have here is that the aggregate or the global rate of profit of the empirical or the real system of production is given in terms of a ratio of heterogeneous goods. Since it is a ratio of heterogeneous goods, its value is unknown.

In the above given example, if the aggregate or the global rate of profit of the system is given by $R$, then the value of $(1+R)=(180 t$. iron $+450 t$. coal $+480 t$. wheat $) /(180 t$. iron +265 t. coal $+410 t$. wheat $)$. Now, if we multiply the physical amounts of iron, coal and wheat by taking several arbitrary prices of iron, coal and wheat, we would find that the value of the above given ratio will change with changes in prices. However, since the physical ratio remains the same, it immediately tells us that prices can create a 'nominal' effect on R (a sort of optical illusion) which is completely independent 
of its physical value. Nevertheless, at this level one can at least establish that the physical ratio of (R) gives us the rate of expansion of this economy, as by multiplying the aggregate of inputs with the physical ratio of $(1+R)$ we get exactly the aggregate of gross output of the system.

Now imagine an equivalent system to the given empirical system which is constructed by reallocating the total labour used in the empirical system in such a way that the proportion of its aggregate inputs and its aggregate outputs are equal for all the basic goods of the system. This is nothing but Sraffa's Standard system, which produces

\section{Standard net income:}

120t. iron $+160 t$. coal +80 qr. wheat $+1 / 4$ labour $\rightarrow 240 t$. iron

40t. iron $+100 t$. coal +120 qr. wheat $+1 / 4$ labour $\rightarrow 360 t$. coal

40t. iron +40 t. coal +200 qr. wheat $+2 / 4$ labour $\rightarrow 480$ qr. wheat

In this imagined equivalent system the global rate of profit or the ratio of the aggregate physical net output to the physical aggregate inputs can be known without the knowledge of prices since it is a ratio of heterogeneous goods made up in the same proportion. This ratio is completely independent of prices; $=$ no matter what prices prevail, it will not affect the global rate of profit of the Standard system. Let us say that this ratio is equal to a number $\mathrm{R}^{*}$; in our example it is equal to $20 \%$. Thus, we come to our first conclusion that as far as the Standard system is concerned, its global rate of profit is the physical property of the system of production and its value is known independently of prices. However, since the real system is nothing but an equivalent system to the Standard system, the physical rate of profits in the two systems must be equal (i.e. $\mathrm{R}^{*}=\mathrm{R}$ ) as the real system is nothing but the rescaled Standard system. 
Suppose we start with the Standard system and an arbitrary set of prices that gives different rates of profit for different sectors in the Standard system, but its global rate of profits would nevertheless be equal to $\mathrm{R}^{*}$. We keep those prices constant and convert the system back to its real state. Since we have kept all the prices constant, it implies that the individual or sectoral rates of profits would remain constant as well. However, since the weights of the sectors have changed in moving from the Standard to the real system, the unequal rates of sectoral profits would most likely result in deviating the global rate of profit $\mathrm{R}$ of the real system from $\mathrm{R}^{*}$. This contradicts the property of equivalent systems. Thus the sectoral rate of profits must be equal to ensure that $\mathrm{R}=\mathrm{R}^{*}$. Let us suppose that in a highly unlikely but mathematically possible scenario, the prices are such that for the real system $R=R^{*}$, but the sectoral rates of profit are still not equal. However, the property that $\mathrm{R}=\mathrm{R}^{*}$ must hold for all the possible imaginary reallocation of the total labour of the real system ensures that the sectoral rates of profit must be equal as even a slight change in the allocation of labour would ensure that $\mathrm{R}$ would diverge from $\mathrm{R} *$ for that given set of prices (see the mathematical appendix for a formal proof). In other words, as long as equations remain the same, the global rates must remain equal for all the input-output configurations, and this is possible if and only if all the sectoral rates of profits are equal. A positive real wages will not affect the analysis as long as the wages are measured by the Standard commodity, which is a composite commodity made up of all the basic goods put together in the Standard proportion.

In the Production of Commodities, Sraffa seems to be arguing in a similar manner when he declares that the mathematical property of the rate of profit of the Standard system commutes to the real system: 
But the actual system consists of the same basic equations as the Standard system, only in different proportions; so that, once the wage is given, the rate of profits is determined for both systems regardless of the proportions of the equations in either of them. Particular proportions, such as the Standard ones, may give transparency to a system and render visible what was hidden, but they cannot alter its mathematical properties (Sraffa 1960, p. 23).

The reader should note that Sraffa could not implicitly assume that supplies were equal to their effectual demands for both the real and the Standard systems; it would be bizarre to assume that the effectual demands were in Standard proportion. Sraffa could not impose the condition of uniform rate of profits on his Standard system on the basis of the socalled implicit assumption that the system is at its centre of gravitation. Thus the rate of profit of the Standard system that Sraffa is referring to above is the global rate of profit of the Standard system, and the claim is that the two global rates must always be equal as long as the wages are measured by the Standard commodity. It is the proposition regarding the equality of the global rate of profits of the rescaled systems that allows Sraffa to deduce directly that all the sectoral or industrial rates of profits must also be uniform in the two systems, as we have argued above. This point becomes absolutely clear in the paragraph immediately following the above quoted passage:

The straight-line relation between the wage and the rate of profits will therefore hold in all cases, provided only that the wage is expressed in terms of the Standard product. The same rate of profits, which in the Standard system is obtained as a ratio between quantities of commodities, will in the actual system result from the ratio of aggregate values. (Sraffa 1960, p. 23).

The reader should note that both the ratios of "quantities of commodities" and of "aggregate values" are well defined only at the global level and have no meaning at the local or industrial level. 
Further on, in his unpublished notes written in 1955, we find that Sraffa invokes similar reasoning behind the possibility of an existence of a Standard commodity:

With changes in $\mathrm{w}--$

The impulse towards price change is an internal one to each industry. It arises from its own internal conditions - not from those conditions compared with those of other industries. Hence the possibility of an invariable commodity. (PSP D3/12/59, emphasis in original).

The reader should yet again note that here Sraffa specifically and with emphasis denies the cause of changes in prices due to conditions compared with other industries, which is the sole cause of the gravitation mechanism; it is the comparison of the rates of profits across sectors that give rise to the gravitation mechanism.

The intuitive reasoning behind Sraffa's result comes from the property of the Standard system. One can clearly see in the Standard system that its global rate of profit is a 'non-price phenomenon'; it is apparently embedded in the physical system of production of commodities by means of commodities. As Sraffa in another note of 1955 wrote,

$\ldots$, the rate of profits at the various individual levels of $\underline{\mathrm{w}}$ will be $\mathrm{r}=\mathrm{R}(1-$ w). Individual prices will move in all directions with the variation of $\underline{w}$, but here again prices will make no difference: $\underline{r}$ is a ratio between two quantities of the same composite commodity and can actually be discovered before knowing what those prices are. The rate of profit is embedded 'in the things' and no manipulation of prices could ever affect it. [There could be no more tangible evidence of the rate of profits [being, as] a non-price phenomenon (effect)]. (PSP D3/12/53, all parentheses and brackets are in original).

This finding shows that uniformity of the rate of profits in the system has nothing to do with the equalization of the supplies with their effectual demands. ${ }^{4}$ As a matter of fact,

\footnotetext{
${ }^{4}$ Joan Robinson (1961) had come closest to understanding this as she claimed that the "clue" to understanding the PCMC could be found in the 'corn model' of Sraffa's (1951) 'Preface' to Ricardo's Principles. In the 'corn model' (e.g. 1 ton of corn produces 1.5 tons of corn), the rate of profit is $50 \%$ no matter what is the final demand for corn. This physical relationship between inputs and outputs that is
} 
relative prices cannot go anywhere they like; they are completely constrained by the system of production and the condition of its reproduction. In some sense Sraffa's result points to a break in economics similar to the break from classical mechanics to quantum mechanics. ${ }^{5}$ The classical and neoclassical economics treat individual industries as independent entities, which through their interaction generate centres of gravitation that bring a system into being. Sraffa's result shows that the system is not made up of independent industries but must be treated as an interconnected whole unit where the properties of the whole determine the properties of its parts.

\section{Interpretation of Sraffa and the notion of 'Centre of Gravitation'}

Our interpretation of equal rate of profits in Sraffa's system stands in stark contradiction to the almost universally received opinion that equal rate of profits in Sraffa's system is based on his implicit assumption of the classical notion of centre of gravitation working behind the scene. It is imperative that we test the strength of this argument if our alternative interpretation has any chance of general acceptability. As we have noted in the Introduction, in the very first sentence of the "Preface' to the book, Sraffa announced that "Anyone accustomed to think in terms of the equilibrium of demand and supply may be inclined, on reading these pages, to suppose that the argument rests on a tacit assumption of constant returns in all industries. ... In fact, however, no

palpably evident in a single basic good model is obscured in n-basic goods model, but Sraffa's analysis with the help of the Standard system reveals that the insight of the corn model remains valid in a more general case as well.

5 It may be noted that Sraffa was well aware of the developments in quantum mechanics. As early as 1928 , he had noted down a passage from H.S. Allen's paper on 'The Quantum Theory' published in Nature, where Allen writes, "Heisenberg put forward the demand that only such quantities as are observable should be represented in the mathematical formulation of atomic theory. ... This led to the development of the matrix mechanics, every term in a matrix corresponding to something which is, at least ideally, observable." (PSP D1/9). Of course, Sraffa makes the same demand for economic theory. Furthermore, Professor Heinz Kurz has informed Sinha that "There are several books devoted to (what was then) modern physics in Sraffa's library. And in some of that there are annotations. Not many, but apparently Sraffa had read or at least skimmed through the books. In his papers he also refers to books that are not in his library, e.g. Bridgman." 
such assumption is made" (p. v). We are encouraged to think that Sraffa's reference to equilibrium of demand and supply refers only to the neoclassical demand and supply functions and not classical equilibrium of demand and supply points. If that were the case, then why didn't Sraffa, a very careful author, say so? Actually the statement refers to 'equilibrium' of demand and supply in general and not of any specific kind. The author is simply asking the reader not to bring the baggage of the notion of 'equilibrium' to his book.

The received interpretation of this uncomfortable announcement, however, is as follows: Sraffa's system is of given output, so the outputs don't move and, therefore, no assumption of returns to scale is needed. ${ }^{6}$ So far so good! But on what grounds one could argue that the rate of profits must be equal in all sectors for those given outputs? Here the argument is that the outputs are assumed to be at their centre of gravitation; therefore Sraffa imposes equal rate of profits on all the sectors. Before we test the argument in the light of the evidence, let us remark that there has been no proof forthcoming that the classical centre of gravitation is a sound theoretical concept in itself. Steedman (1984) made highly simple arguments to highlight that the so-called centre of gravitation may not be an attractive point for the system and Dupertuis and Sinha (2009) have shown in a comprehensive manner that the classical notion of the centre of gravitation is not an attractive point. Given that Sraffa had analysed the highly intricate nature of prices in a complex interconnected system in his chapters on Reduction to Dated Labour, Multiple Production, and Switch in Techniques, it touches on credulity to think that he would have

\footnotetext{
${ }^{6}$ Neoclassical detractors of Sraffa have also accused him of implicitly (and without understanding) assuming constant returns to scale. See Samuelson (2000a, 2000b), Samuelson and Etula (2006) for such argument and Sinha (2007) for a critique of Samuelson.
} 
no misgivings about the existence of the centre of gravitation and could go on to claim that the rate of profits must be equal on its basis.

Now, we begin our analysis of the claim that Sraffa takes 'effectual demand' as given data of the theory and his given quantity is taken as equal to the given 'effectual demand'. Garegnani (1976, 1984, 1990a, 1990b, 1990c, 1990d, 1998, 2000) has been in the forefront of providing the Sraffian reading of the classical economists that apparently squares with Sraffa's claim of the 'classical standpoint' of a 'given output' with the notion of the 'centre of gravitation'. It is, however, universally accepted, even by Professor Garegnani himself, that the classical economists did not believe that the actual supplies of any given system at any given point of time were equal to the given effectual demands. Thus we have two sets of given data available at any point of time: one is the 'effectual demand' data, and another is the actual data of inputs and outputs at any point of time. If the two sets are not equal, then equalizing the supplies with the "effectual demands' while keeping the proportions of the given input-output data constant would amount to assuming constant returns, which is what the classical economists do. Since there are no production functions available in the context of classical economics or Sraffa's book, there is no way of avoiding CRS if one wants to assume that the given supply quantities are equal to the given 'effectual demands'. This was the reason why Sraffa at the very outset proclaimed that his system does not require thinking in terms of equilibrium of demand and supply.

To avoid such pitfalls Garegnani (1990a, p. 132) maintains that Sraffa's given outputs are ex-ante and not ex-post, as he writes, "The outputs he [Sraffa] takes as given are ex ante normal outputs just like the neoclassical 'equilibrium' outputs...”. In his 
'Comments' on Asimakopulos's paper in the same volume, Garegnani gives a glimpse of what he could mean by taking the 'social physical product' as given. It appears that he thinks that the ex ante outputs that the theoretician takes as given is some sort of average of several years of actual outputs: “...(the actual magnitude corresponding to it [Sraffa's system], would, if anything, be a moving average calculated over several years)" (Garegnani 1990c, p. 350). If Sraffa's outputs are the averages of several past years of outputs, then what are his inputs? They must also be the averages of the inputs of the same past years. Thus the representative technique of Sraffa turns out to be simple averages of the input-output data of past several years. However, a representation of such an average technique is possible only if constant returns are assumed.

Furthermore, an attribution of such a procedure to Sraffa contradicts his two fundamental methodological principles. First of all, the averages (or the average technique) are unobservables; they may not exist in reality. Sraffa's principle, however, was to build his theoretical propositions only on things that can at least be ideally observable. Second, Sraffa's prices and the rate of profits are precise and not some kind of statistical averages. In a note after the publication of the $P C M C$, Sraffa wrote, "The wage and the aggregate profit of reality are, at best, rough approximations of the standard wage and profit. But the rate of profit of reality is identical to that of the standard" (PSP D3/12/111/139, the English translation from the original in Italian is quoted in Gehrke 2007). Of course, such a statement would be incorrect if his input-output data were not the data of the real system in use but rather a representative average of past several years. The above statement by Sraffa further reinforces our interpretation that the uniformity of 
the rate of profits in Sraffa's system is not contingent on the system being at the centre of gravitation.

Moreover, in Chapter III of the PCMC Sraffa works out complicated changes in prices due to changes in the distribution of the net output, all the while keeping the gross as well as the net output constant. Unless it is assumed that both the capitalists and the workers receive their income in exactly the same commodities and in the same proportions, it simply cannot be maintained that all those price solutions would be the equilibrium prices or the given output would conform to the effectual demand for the various income distributions. No such assumption, however, is made in the book! ${ }^{7}$

Furthermore, in Appendix B (pp. 90-91) Sraffa deals with a curious case of a nonbasic commodity which uses itself at a very high proportion in its own production, say 100 units of 'beans' are needed to produce 110 units of 'beans'. In this case, the rate of profit in the 'beans' sector cannot be more than $10 \%$, but if the rate of profits in the basic goods sectors happens to be more than $10 \%$, then there cannot be equal rate of profits in all the sectors with all prices being positive. This case would simply not arise if one assumed that Sraffa's system dealt only with long-term equilibrium situations since, given the long-term equilibrating mechanism of the market, the 'beans' producing capitalists would simply move out of 'beans' production and move to producing some basic goods resulting in disappearance of the 'beans' from the system. Thus Sraffa's

\footnotetext{
${ }^{7}$ In a recent paper Garegnani (2005) argues that a fundamental shift in Sraffa's theoretical approach took place in late 1927, and he goes on to show that only afterwards did Sraffa try to relate his new position with the classical economists. In this context Garegnani emphasizes the given output approach of Sraffa and the classical economists without bringing up the notion of centre of gravitation. This might be an indication that Garegnani's position itself might be shifting on his interpretation of Sraffa's position on the notion of centre of gravitation.
} 
'beans' would be produced only when the system is not in the long-term equilibrium, which is evidence to the effect that his system is not necessarily in long-term equilibrium.

Finally, Garegnani's or the 'Sraffian' position rests on the conviction that Sraffa made several 'implicit assumptions' of an empirical nature on his system of equations, but it cannot be sustained against a careful reading of the book. In the book we find that Sraffa is extremely particular about stating his empirical assumptions even when they are of an unproblematic nature. For example, there is no logical reason for any good in Sraffa's system to be 'basic'; therefore, Sraffa explicitly writes, "We shall assume throughout that any system contains at least one basic product" (p. 8). More interestingly, on page 10 we are told, "We retain however the supposition [of the classical economists] of an annual cycle of production with an annual market." Again, in the context of jointproduction there is no logical necessity that the number of processes and the number of goods be equal. In Sraffa's context it depends upon the assumption that the proportions in which commodities are produced by any one method are different from the proportions in which they are required for use. This is a mild assumption for any given empirical system, but it is explicitly made and on its basis Sraffa goes on to state, "(The assumption previously made of the existence of 'a second process' can now be replaced by the more general assumption that the number of processes should be equal to the number of commodities)" (p. 44). However, if Sraffa was assuming that his system of equations was based on a particular empirical assumption that its outputs correspond to given effectual demands, then why didn't he make this assumption explicitly in this case? Why would he begin the book by telling the reader not to think in terms of equilibrium of demand and supply and then go on implicitly to assume exactly the same thing? 
Before closing this section, let us look critically at the evidence provided in support of the received interpretation that Sraffa's prices are the centers of gravitation prices of the classical economists. If what we say above is true, then what could Sraffa mean by stating in the 'Preface', "This standpoint [i.e. of given output], which is that of the old classical economists from Adam Smith to Ricardo, has been submerged and forgotten since the advent of the 'marginal' method [p.v]", as the gravitation mechanism was clearly part of Adam Smith's and Ricardo's systems? The answer to this question can be found in one of Sraffa's notes of the period of his early breakthrough:

When A. Smith etc. said 'natural' he did not in the least mean the 'normal' or the 'average' nor the 'long run' value. He meant that physical, truly natural relations between commodities, that is determined by the equations, and that is not disturbed by the process of securing a greater share in the product. ... (PSP D3/12/11, quoted in Garegnani 2005, p. 474).

Clearly, from the beginning of his new theoretical adventure Sraffa had completely discounted the notion of 'centre of gravitation' as part of the 'classical standpoint'. The reader should note that we are here not concerned with the "correctness" of Sraffa's reading of Adam Smith. The evidence shows that when Sraffa uses the word "natural price" of classical economists, he is not using it as the long-term equilibrium or centre of gravitation price. ${ }^{8}$ It should also be noted that in his lecture notes of 1928 Sraffa spends a lot of time on the classical theory of value. However, it is the objective aspect of the

\footnotetext{
${ }^{8}$ A referee of another journal suggested that we are contradicting ourselves by first suggesting that Sraffa's understanding of equal rate of profits might have emerged after his discovery of the Standard system in the $40 \mathrm{~s}$ with the claim that he discounted the centre of gravitation argument as of late 1927. There is no contradiction here though Sraffa had discounted the centre of gravitation argument with his early breakthrough because the centre of gravitation argument rests on the behavior of the agents, a subjective notion. However, he did not know how else to rationalize the requirement of the equal rate of profits in his system. This was his struggle that we have highlighted. This struggle could have come to an end after he discovered the Standard system.
} 
classical theory of value that is emphasized there and the notion of the centre of gravitation is completely ignored.

Furthermore, Sraffa also refers to the approach of his book being "reminiscent to certain points of view taken by the old classical economists from Adam Smith to Ricardo...” (back cover, Sraffa 1960). They are all listed in Appendix D of the book: (1) Quesnay's Tableau Economique is credited for the circular point of view, (2) the notion of basic goods could be discerned in Ricardo's 'corn model', (3) the idea of the Standard commodity could also be discerned in Ricardo, (4) the notion of maximum rate of profits is found in Marx, and (5) the treatment of fixed capital as a kind of joint-product could be found in Torrens. Interestingly, we find that there is no reference to the notion of "natural prices" or the "centre of gravitation" in the list. If Sraffa had accepted the notion of the centre of gravitation in his book, then why did he not acknowledge Adam Smith for this idea?

Anyway, the most important evidence that is invoked in favor of the received interpretation is Sraffa's statement $(1960$, p. 9) that "Such classical terms as 'necessary price', 'natural price' or 'price of production' would meet the case, but value and price have been preferred as being shorter and in the present context (which contains no reference to market prices) no more ambiguous." A closer reading of this passage, however, confirms our interpretation and rejects the received interpretation. As we have shown above, quantitatively Sraffa's price is the same as Smith's and Ricardo's 'natural price' and Marx's 'price of production' (if we append a CRS assumption to Sraffa's equations); however, Sraffa's price is not defined to hold only at the centre of gravitation. Thus it does not need any reference to 'market prices'. Sraffa's caveat that his context 
"contains no reference to market prices" takes away the essential element of the gravitational mechanism. It is the "market prices" that gravitate toward the centers of gravitation in the classical system. What meaning could be assigned to a concept whose essential complement is deliberately left out of the theoretical context? Can we imagine a centre of gravitation in a space without matter?

\section{Some Concluding Remarks}

If what we say above is true, then how does the system react if there are excess demands and supplies in the system? The answer, of course, must lie in quantity movements. The logic of gravitational mechanism suggests that when quantity supplied of a commodity is below the quantity demanded, then the demanders will raise its price, and in the case of quantity supplied being higher than the quantity demanded, the suppliers will lower the price; but one can raise or lower the prices only from some given prices. As a matter of fact, if quantity demanded of a commodity depends on its price, then the price must be given before the excess demand or supply of a commodity could be determined. In the neoclassical general equilibrium theory, these given prices are announced by an auctioneer, but neither the classical economics nor Sraffa has the instrument of the auctioneer. Sraffa's solution to prices, which is the internal solution of the system of production as a whole, is the solution of what could be interpreted as 'offer' prices that suppliers would make. Let us suppose that there are excess demands and supplies on those 'offer' prices that lead to rise and fall in the prices in the market and which are taken as signals for the rescaling of the sectors in the next time period, but in the next time period, if the equations have remained the same, the suppliers will offer new quantities exactly at the same 'offer' prices. Thus 'market prices' may guide the 
system towards equilibrium but cannot change the 'offer' prices as the system moves from disequilibrium to equilibrium position. As a matter of fact, on the assumption of CRS, Dupertuis and Sinha (2009) have shown that such fixed-price quantity adjustments are the only adjustment mechanisms that are compatible with the centres of gravitation. It should, however, be noted that such quantity adjustments requires the assumption of constant returns to scale. Sraffa did not consider any equilibrating mechanism, so he did not need to make any such assumption. He simply dissolves the problem of 'equilibrium' for a theory of price. 


\section{References}

Dupertuis, M.-S., Sinha., A., 2009. A Sraffian critique of the classical notion of centre of gravitation. Cambridge Journal of Economics (Forthcoming, already on line).

Garegnani, P., 1976. On a change in the notion of equilibrium in recent work on value and distribution: A comment on Samuelson. In: Brown, M., Sato, K., Zarembka, P. (Eds.). Essays in Modern Capital Theory. Amsterdam: North Holland, 25-45.

Garegnani, P., 1984. Value and distribution in the classical economists and Marx. Oxford Economic Papers 36, 291-325.

Garegnani, P., 1990a. Sraffa: Classical versus Marginalist analysis. In: Bharadwaj, K., Schefold, B., (Eds.). Essays on Piero Sraffa: Critical Perspectives on the Revival of Classical Theory. Delhi: Oxford University Press, 112-140.

Garegnani, P., 1990b. Reply. In: Bharadwaj, K., Schefold, B., (Eds.). Essays on Piero Sraffa: Critical Perspectives on the Revival of Classical Theory. Delhi: Oxford University Press, 148-158.

Garegnani, P., 1990c. Comment. In: Bharadwaj, K., Schefold, B., (Eds.). Essays on Piero Sraffa: Critical Perspectives on the Revival of Classical Theory. Delhi: Oxford University Press, 345-52.

Garegnani, P., 1990d. Quantity of capital. In: Eatwell, J., Milgate, M., Newman, P. (Eds.). The New Palgrave Series: Capital Theory. London: Macmillan, 1-78.

Garegnani, P., 1998. Sraffa: The theoretical world of the "old classical economists". The European Journal of the History of Economic Thought 5, 415-429.

Garegnani, P., 2000. Savings, investment and the quantity of capital in general intertemporal equilibrium. In: Kurz, H. (Ed.). Critical Essays on Piero Sraffa's Legacy in Economics. Cambridge: Cambridge University Press, 392-445.

Garegnani, P., 2005. On a turning point in Sraffa's theoretical and interpretative position in the late 1920s. The European Journal of the History of Economic Thought 12, 453-492.

Gehrke, C., 2007. Sraffa's correspondence relating to the publication of Production of Commodities by Means of Commodities: Some selected material. Paper presented at ESHET Annual Meeting, Strasbourg, 2007.

Hahn, F., 1982. The neo-Ricardians. Cambridge Journal of Economics 6, 353-374.

Harrod, R.F., 1961. Review of Production of Commodities by Means of Commodites. Prelude to a critique of economic theory. The Economic Journal 71, 783-787.

Hicks, J., 1985. Sraffa and Ricardo: A critical view. In: Caravale, G.A. (Ed.). The Legacy of Ricardo. New York: Basil Blackwell, 305-319.

Robinson, J., 1961. Prelude to a critique of economic theory. Oxford Economic Papers $13,53-58$. 
Roncaglia, A., 1978. Sraffa and the Theory of Prices. Chichester: John Wiley \& Sons.

Samuelson, P.A., 2000a. Sraffa's hits and misses. In: Kurz, H.D. (Ed.). Critical Essays on Piero Sraffa's Legacy in Economics. Cambridge: Cambridge University Press, 111-151.

Samuelson, P.A., 2000b. Reply. In: Kurz, H.D. (Ed.). Critical Essays on Piero Sraffa's Legacy in Economics. Cambridge: Cambridge University Press, 163-180.

Samuelson, P., Etula, E.M., 2006. Testing to confirm that Leontief-Sraffa matrix equations for input/output must obey constancy of returns to scale. Economics Letters 90, 183-188.

Sinha, A., 2007. Sraffa and the assumption of constant returns to scale: A critique of Samuelson and Etula. Contributions to Political Economy 26, 61-70.

Sinha, A., Dupertuis, M.-S., 2009. Sraffa and the question of equilibrium. Cahiers d'économie politique, forthcoming.

Sraffa, P., 1960. Production of Commodities by Means of Commodities. Cambridge: Cambridge University Press.

Sraffa, P., 1962. Production of commodities. A comment. The Economic Journal 72, 477479.

Sraffa, P., ND. Piero Sraffa Papers. Wren Library, Trinity College, Cambridge.

Steedman, I., 1984. Natural prices, differential profit rates and the classical competitive process. The Manchester School of Economic and Social Studies 52, 123-140.

\section{Acknowledgement}

We wish to thank Christian Bidard, Duncan Foley, Pierangelo Garegnani, Roger Guesnerie, Geoffrey Harcourt, Samuel Hollander, John King and Gary Mongiovi for valuable comments on the first part of the earlier drafts of this paper. Sinha would also like to thank Professor Garegnani, the literary executor of Sraffa's unpublished papers, for his permission to publish excerpts from Sraffa's unpublished papers, and also to the very helpful staff of the Wren Library, Trinity College, Cambridge, where Sraffa's papers are housed. 


\section{Mathematical Appendix}

\section{Stable point in Sraffa's system: the mathematical proof}

\section{Basic notations}

Let's start with an example we encountered previously:

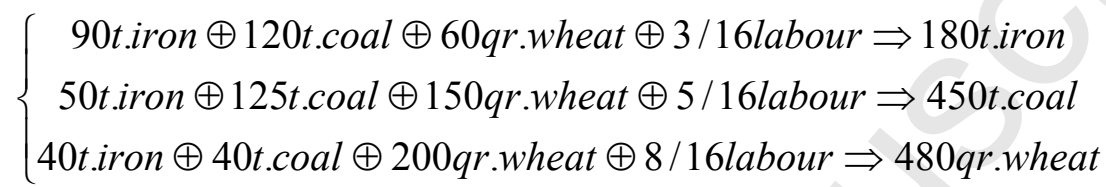

Such a system does not represent simple "additions" but a whole machinery.

Let's think of a $n$ sectors economy with single commodity production. Whatever these sectors are, let us number the commodities from 1 to $n$. In the " $i$ " sector (i.e. the production unit of product $i$ ), the entries are quantities $a_{i, j}$ with respect to the commodities numbering, the amount of labour is denoted $l_{i}$ and the output is $q_{i}$. Thus, the system $(\mathrm{S})$ is

$$
\text { (S) } \quad(\forall i) \quad a_{i, 1} \oplus \cdots \oplus a_{i, n} \oplus l_{i} \Rightarrow q_{i} \text {. }
$$

Such a system can be represented by a matrix and two vectors. Let's define

$$
\begin{aligned}
& A=\left(a_{i, j}\right) \\
& L=\left(l_{i}\right) \\
& Q=\left(q_{i}\right)
\end{aligned}
$$

where $L$ and $Q$ are column vectors. Then the system can be written

$$
\text { (S) } \quad A \mid L \Rightarrow Q \text {. }
$$

Each line corresponds to one production unit. From now, we will only consider viable systems, which means that the following conditions should be satisfied: 
- the matrix $A$ is invertible with non negative entries;

- all the outputs $q_{i}$ are strictly positives;

- the total amount of labour is equal to 1 (but this is not a necessary assumption);

- there are no independent or 'non-basic' commodities;

- each $q_{i}$ is strictly greater than $a_{i, i}$.

\section{Proposition}

For a fixed choice of prices, the global rate of profit is independent of rescaling if and only if the local rates of profit are all equal, in which case the global and local rates of profit are equal to the standard rate.

Local rate of profit: Given a system of prices, the rate of profit of sector $i$ is the number $R_{i}$ satisfying

$$
(\mathrm{RP} 1)\left(1+R_{i}\right)\left(\sum_{j} a_{i, j} p_{j}\right)+l_{i} w=q_{i} p_{i} .
$$

In terms of matrices, the local rates of profit are given by

$$
\text { (RP2) } \widetilde{R} A P=(\widetilde{Q} P-A P-w L)
$$

where $\widetilde{Q}$ is the diagonal matrix whose diagonal coefficients are the coordinates of $Q$ and $\widetilde{R}$ and $\widetilde{L}$ are the diagonal matrices whose diagonal entries are the rates of profit and the amount of labour respectively and where $R$ and $P$ are the column vectors whose entries are rates of profit and prices respectively.

Global rate of profit: The global profit of the system is the number $R_{G}$ defined by 


$$
\left(1+R_{G}\right) \sum_{i} \sum_{j} a_{i, j} p_{j}=\sum_{i} q_{i} p_{i}
$$

In other words, it's the rate of profit made by the system as a whole. The global rate of profit can be computed from local rates of profit via

$$
\text { (GR) } \quad R_{G}=\frac{e \bullet(\widetilde{Q}-A) P}{e \bullet A P}=\frac{e \bullet \widetilde{R} A P}{e \bullet A P} \text {. }
$$

\section{Lemma 1}

A system is standard if and only if its global rate of profit is constant, in which case it is equal to the standard rate.

Proof:

Let's suppose that the global rate of profit is a constant $r$. Then, for all vector $v$, one has

$$
0=e \bullet(\widetilde{Q}-(r+1) A) P=\left(I-(r+1) \widetilde{Q}^{-1} A^{t}\right) e \bullet \widetilde{Q} P=(r+1)\left(\frac{1}{(r+1)} I-\widetilde{Q}^{-1} A^{t}\right) e \bullet \widetilde{Q} P
$$

Since this is true for all prices and since matrix $\widetilde{Q}$ is invertible, one concludes that $r$ is the standard rate and that $e$ is an eigenvector of matrix $\widetilde{Q}^{-1} A^{t}$ for the eigenvalue $\rho$. In short, one has $\Lambda=e$ which means that the system is standard.

Conversely, if the system is standard, one has $A^{t} e=\rho Q$. Thus,

$$
R_{G}=\frac{e \bullet(\widetilde{Q}-A) P}{e \bullet A P}=\frac{e \bullet \widetilde{Q} P}{e \bullet A P}-1=\frac{\widetilde{Q} e \bullet P}{e \bullet A P}-1=\frac{1}{\rho} \frac{A^{t} e \bullet P}{e \bullet A P}-1=\frac{1}{\rho} \frac{e \bullet A P}{e \bullet A P}-1=\frac{1}{\rho}-1
$$


Rescaling: Let $\mu_{1}, \ldots, \mu_{n}$ be strictly positive numbers, and let $M$ be the diagonal matrix whose diagonal entries are these numbers. The rescaled system obtained by multiplying the $i$ line by $\mu_{i}$ is $M A \mid M L \Rightarrow M Q$. Two systems that differ only from rescaling have the same standard system.

\section{Proof of the Proposition:}

Suppose that $R_{G}$ is independent of rescaling. Let's recall that

$$
R_{G}=\frac{e \bullet \widetilde{R} A P}{e \bullet A P}
$$

Since local rates are independent of rescaling and since diagonal matrices commute between themselves, for any rescaling matrices $M$ and $N$, one has

$$
R_{G}=\frac{e \bullet \widetilde{R} M N A P}{e \bullet M N A P}=\frac{M e \bullet \widetilde{R} N A P}{M e \bullet N A P} .
$$

Therefore, for any diagonal matrices $M$ and $N$,

$$
M e \bullet\left(\widetilde{R}-R_{G} I\right) N A P=0
$$

where $I$ is the identity matrix.

Thus, for any diagonal matrix $N$,

$$
\left(\widetilde{R}-R_{G} I\right) N A P=0
$$

and, finally, one obtains $\widetilde{R}=R_{G} I$. The conclusion follows from the fact that when the local rates of profits are equal, then they are equal to their global rate, which in turn is equal to the Standard rate or the global rate of profit of its Standard system.

Conversely, if $\widetilde{R}=R_{G} I$, then, by the above fact, the global rate is equal to the standard rate and, thus, is independent of rescaling. 
Let's note that the matrices $M$ and $N$ in the proof of this proposition only need to be close to the identity matrix. This means that if the global profit does not change even for tiny rescaling, then the global rate and the local rates are all equal to the standard rate. The last proposition means that the point where local rates of profit are equal is a stable point; in fact, it is the only point which is unaffected by rescaling. One should be aware that there are sets of prices for which the global rate is equal to the standard rate and the local rates are unequal. However, for any of these sets, there exists rescaling that changes the global rate of profit. 